\title{
Moderate iodine deficiency among pregnant women in Hong Kong: revisit the problem after two decades
}

\author{
WH Tam *, Ruth SM Chan, Michael HM Chan, LY Yuen, Liz Li, Mandy MM Sea, Jean Woo
}

\section{A B S T R A C T}

Introduction: A survey conducted during 2005 to 2007 by the Centre for Food Safety in Hong Kong suggested that only $5 \%$ of the local population had a sufficient dietary intake of iodine. The study, however, was limited as biochemical data (ie urinary iodine concentration) were lacking. Pregnant women are vulnerable to iodine deficiency because of their increased requirement. Recent studies have shown that iodine deficiency in early pregnancy is associated with poorer cognitive development in early childhood. This study reports the iodine status of women during early gestation at an obstetric unit in Hong Kong.

Methods: Healthy pregnant women with no history of hyperemesis gravidarum were enrolled into a study when they first made a booking in an antenatal clinic of a public hospital to investigate their iodine status during early pregnancy. All subjects were asked to collect their morning urine for measurement of iodine and creatinine levels. Daily dietary intake of iodine was assessed in a subgroup of participants by structured interview using a standard food frequency questionnaire.

This article was published on 10 Nov 2017 at www.hkmj.org.
Results: A total of 600 pregnant women were enrolled at a median of 7.0 weeks of gestation. The median urinary iodine concentration and urinary iodine-to-creatinine ratio were $100 \mu \mathrm{g} / \mathrm{L}$ and $98 \mu \mathrm{g} / \mathrm{g}$, respectively; 429 (71.5\%) participants had iodine insufficiency according to the World Health Organization classification. Daily dietary intake of iodine was assessed in 146 participants. The median daily intake of iodine was $69.5 \mu \mathrm{g}$ and 122 (83.6\%) participants had an intake below the $250 \mu \mathrm{g}$ recommended during pregnancy by the World Health Organization.

Conclusions: Local pregnant women continue to have an inadequate dietary intake of iodine and remain iodine-deficient.

\section{Hong Kong Med J 2017;23:586-93}

\section{DOI: 10.12809/hkmj176841}

\author{
${ }^{1}$ WH Tam *, MD, FRCOG \\ ${ }^{2}$ RSM Chan, PhD \\ ${ }^{3}$ MHM Chan, FRCPA, FHKCPath \\ 1 LY Yuen, BSc \\ ${ }^{2} \mathrm{LLi}, \mathrm{MSC}$ \\ ${ }^{2}$ MMM Sea, PhD \\ ${ }^{2} \mathrm{~J}$ Woo, MD, FRCP \\ 1 Department of Obstetrics and Gynaecology \\ ${ }^{2}$ Department of Medicine and Therapeutics \\ ${ }^{3}$ Department of Chemical Pathology \\ The Chinese University of Hong Kong, Shatin, Hong Kong
}

* Corresponding author: tamwh@cuhk.edu.hk

New knowledge added by this study

- This study confirmed the previous observation that dietary intake of iodine is inadequate in our local population, in particular in women during pregnancy.

- The majority of the pregnant women were taking multivitamin supplements without iodine, suggesting inadequate knowledge about the importance of iodine.

Implications for clinical practice or policy

- There is an urgent need to educate the general public, in particular women of childbearing age, about the importance of an adequate dietary intake of iodine and the option of iodine-containing multivitamin supplements before contemplating pregnancy.

- We can consider a policy to monitor the iodine status of the population, especially in vulnerable groups including pregnant and lactating mothers, and their children.

- World Health Organization recommends salt iodisation in countries and areas that are iodine-deficient. As less than $15 \%$ of table salt available in Hong Kong is iodised, it may be appropriate to consider this policy.

\section{Introduction}

The World Health Organization (WHO) considers iodine deficiency the single most important preventable cause of brain damage worldwide.
Since 1993, WHO has recommended universal salt iodisation to eliminate iodine deficiency disorder. ${ }^{1}$ There is a common belief that the Hong Kong population residents in coastal regions should have 
sufficient iodine intake. Twenty years ago, however, $50 \%$ of children and adults were found iodinedeficient according to the WHO standards. ${ }^{2}$ At the same time, studies also reported that one third of local pregnant women were iodine-deficient based on their urinary iodine concentration (UIC), from the first through third trimester. ${ }^{3,4}$ Pregnant and lactating women are among the most vulnerable groups in the population as iodine plays an important role in early neuronal migration and maturation in the developing fetus and infants.

A local expert panel group was established in 2003 to encourage the monitoring of iodine status and rectify the problem. ${ }^{5}$ The panel concluded that dietary iodine intake of our population was borderline sufficient, and was also inadequate to meet any extra requirement at the time of thyroid stress, ie pregnancy, neonatal period, and in the first few years of life. ${ }^{5}$ In a local population survey conducted by the Centre for Food Safety during 2005 to 2007, the median iodine dietary intake was as low as $44 \mu \mathrm{g} /$ day among 5000 adults, while $60 \%$ had an intake of $<50 \mu \mathrm{g} /$ day (the threshold for normal thyroid functioning). ${ }^{6}$ Only $5 \%$ had an iodine intake within the safe range. This report, however, also admitted a lack of clinical and biochemical data (ie UIC) that precluded a conclusion about iodine deficiency. Since this report in 2011, all mothers are enquired about their dietary intake of iodine and provided with iodine-containing multivitamin supplements when they book in at a Maternity and Child Health Centre in Hong Kong.

Nevertheless, the problem remains unresolved as two recent cohort studies in the UK and Australia consistently reported that low maternal firsttrimester UIC was associated with poorer childhood cognitive development at the age of 8 to 9 years. ${ }^{7,8}$ The investigators of the Avon Longitudinal Study of Parents and Children in the UK also reported a doseeffect association; child neurocognitive scores were lower when maternal urinary iodine-to-creatinine ratio (UICr) was $<50 \mu \mathrm{g} / \mathrm{g}$. $^{7}$

As no salt iodisation programme has been implemented since the first study was carried out, and with the changes in social circumstances and dietary trends over the last two decades, it was deemed necessary and important to reassess the iodine status of pregnant and lactating women in Hong Kong to guide future policy. The objective of this paper was to report the iodine status of women during early gestation at an obstetric unit in Hong Kong.

\section{Methods}

Between July 2014 and November 2015, healthy pregnant women were enrolled at the antenatal clinic of Prince of Wales Hospital into a study of gestational age-specific thyroid function test

\section{香港孕婦中度缺碘的情況：二十年後問題重溫}

譚永雄、陳淑薇、陳浩明、袁麗玉、李倩、史曼媚、胡令芳

引言：香港食品安全中心於 2005 年至 2007 年進行的一項調查顯示, 只有 $5 \%$ 港人的腼食含有足夠的碘。但該研究卻因缺乏生化檢測數據 （如尿碘濃度水平）而受影響。由於妊娠期對碘的需求量增加, 碘質 缺乏更為明顯。最近的研究顯示, 如妊娠初期缺乏碘, 將來幼兒的認 知能力會相對較差。而本研究的目的是調查本港孕婦在妊娠初期的碘 水平。

方法: 我們邀請來到一所公立醫院專科門診預約產前檢查而沒有妊娠 劇吐情況的孕婦參與本研究, 通過測量她們早上尿液樣本的碘和肌酐 水平來評估她們在妊娠初期的碘是否足夠。同時, 我們會利用標準化 的食物頻率調查問卷去評估部分參與者每日透過膳食攝取的碘含量。

結果：我們共邀請了 600 名於妊娠初期 (中位數為 7.0 週 ) 的孕婦參與 研究。她們的尿碘濃度和肌酐校正的尿碘指標中位數分別為 $100 \mu \mathrm{g} / \mathrm{L}$ 和 $98 \mu \mathrm{g} / \mathrm{g}$ 。根據世界衛生組織所制定的標準, 共有 429 名孕婦 (71.5\%) 缺乏碘。我們利用飲食問卷評估了146名孕婦, 發現她們每 日透過膳食攝取的碘含量中位數為 $69.5 \mu \mathrm{g}$; 當中有 122 人 $(83.6 \%)$ 的攝取量低於世界衛生組織對孕婦所建議的 $250 \mu \mathrm{g}$

結論：本地孕婦透過腼食攝取的碘含量仍然不足, 依舊顯示有缺乏碘 的情況。

reference intervals. Women without a history of thyroid dysfunction, hyperemesis gravidarum, autoimmune disease, or any other major medical conditions were eligible. Consecutive cases were recruited at their first attendance for antenatal booking. We estimated that 250 blood samples were required for each block of gestational age range $(<6$, $6-10,>10-14,>14-18,>18-24,>24-32,>32-38$, and $>38$ weeks) to generate a nomogram; 600 subjects were required to provide 2000 samples, each had an average of four blood samples across the gestation, with an estimated dropout rate of $15 \%$. All subjects underwent early ultrasound scan for dating with gestational age adjusted according to the ultrasound date if it differed to that calculated from the last menstrual period. The study was approved by the Chinese University of Hong Kong Clinical Research Ethics Committee (CRE-2013.500), and written informed consent was obtained from all women.

As part of the study design, UIC was measured at the time of recruitment to determine the participant's iodine status. Women were asked to collect a morning urine sample into an acidwashed trace element urine bottle within 1 week of recruitment for the assay. In this study, UIC was measured by an inductively coupled plasma mass spectrometer (ICP-MS 7700; Agilent Technologies, US). The intra- and inter-assay coefficients of variation for UIC were $3.3 \%$ and $7.4 \%$ at $11.9 \mu \mathrm{g} / \mathrm{L}$, and $2.7 \%$ and $4.9 \%$ at $49.6 \mu \mathrm{g} / \mathrm{L}$, respectively. Urinary 
creatinine concentration was also measured by IDMS-traceable Jaffe kinetic reaction (cobas 8000; Roche Diagnostics Inc, US) to calculate the UICr.

All participants were interviewed by a research nurse who asked about the duration, frequency, and brand of any multivitamin supplements taken to quantify daily iodine supplementation. Due to the limited funding, dietary intake of iodine-containing foods was only assessed in a conveniently sampled subgroup of the population by another research assistant using a food frequency questionnaire (FFQ; Appendix). Education level and occupation were recorded for this subgroup. The FFQ was based on the literature and previously validated FFQs that have been used in the local population..$^{6,910}$ Eleven main food groups that contribute to iodine intake in the local population were incorporated into the FFQ (Table 1). Portions were reported based on standard reference sizes, eg cups, grams, centilitres. To facilitate understanding and recall, food photo albums and eating utensils of standard portions were presented when completing the FFQ. Use of iodised salt was also documented. Daily dietary intake of iodine was calculated using Food Processor Nutrition Analysis and Fitness software, version 8.0 (ESHA Research, Salem, US). The iodine content of local foods was also programmed into the software, extracted from food composition tables from Hong Kong SAR and Mainland China. ${ }^{11}$ We used the WHO definition to categorise insufficient, adequate, above requirements, and excessive by UIC of $<150,150$ $249,250-499$, and $\geq 500 \mu \mathrm{g} / \mathrm{L}$, respectively ${ }^{12}$; UICr of $<150 \mu \mathrm{g} / \mathrm{g}$ was also used to define insufficiency according to Bath et al. ${ }^{7}$ An average daily iodine intake of $250 \mu \mathrm{g} /$ day was considered adequate for pregnancy. ${ }^{1}$ Data are expressed as mean \pm standard deviation (SD), median and interquartile range (IQR), or counts with proportion. Between-group differences were compared using the Student's $t$ test and $X^{2} /$ Fisher's exact tests, as appropriate. Multivariate logistic regression analyses were used to obtain adjusted odds ratios with $95 \%$ confidence intervals, with the forced entry of covariates, namely maternal age, parity, education level, occupation, body mass index, and gestational age at recruitment, to assess factors associated with low UIC $(<150$ $\mu \mathrm{g} / \mathrm{L})$, low $\mathrm{UICr}(<150 \mu \mathrm{g} / \mathrm{g})$ and iodine-containing supplementation. Multivariate linear regression analyses were used to assess the association with UIC and UICr. Statistical analysis was performed using SPSS (Windows version 20.0; IBM Corp, Armonk [NY], US). A P value of $<0.05$ was used to indicate significance for two-tailed statistical test results. The gestational age-specific thyroid function test reference intervals are not included in this article but will be published elsewhere.

\section{Results}

A total of 600 healthy pregnant women were enrolled during the study period at a median gestational age of 7.0 (IQR, 5.9-8.6) weeks. The mean ( \pm SD) age and body mass index at recruitment were $31.3 \pm 3.9$ years and $21.9 \pm 3.1 \mathrm{~kg} / \mathrm{m}^{2}$, respectively. Of the subjects, $382(63.7 \%)$ women were nulliparous and two $(0.3 \%)$ were twin pregnancies. The median (IQR) UIC and UICr were 100 (58-165) $\mu \mathrm{g} / \mathrm{L}$ and 98 (67-150) $\mu \mathrm{g} / \mathrm{g}$, respectively (Table 2 ). According to the WHO definition, $429(71.5 \%)$ participants were regarded as iodine deficient (Fig a). Moreover, 450 (75.0\%)

TABLE I. Contribution to daily dietary intake of iodine from eleven main food groups

\begin{tabular}{|c|c|c|c|}
\hline Food group & $\begin{array}{l}\text { No. (\%) of women } \\
\text { consumed the food } \\
\text { group }\end{array}$ & $\begin{array}{l}\% \text { Of daily dietary intake } \\
\text { of iodine contributed by } \\
\text { the food group* }\end{array}$ & $\begin{array}{l}\text { Mean absolute iodine intake } \\
\text { contributed by the food group } \\
(\mu \mathrm{g} / \mathrm{d}) \text { among all woment }\end{array}$ \\
\hline Seaweeds & $111(76.0)$ & 30.5 & 139.7 \\
\hline Non-alcoholic beverages and soups (including water) & $146(100)$ & 21.5 & 15.0 \\
\hline Milk and milk products including frozen confections & $137(93.8)$ & 15.1 & 13.0 \\
\hline Fish & $146(100)$ & 10.4 & 8.4 \\
\hline Eggs & $141(96.6)$ & 8.8 & 6.8 \\
\hline Meat, poultry, and game & $145(99.3)$ & 4.3 & 3.1 \\
\hline Crustaceans and molluscs & $132(90.4)$ & 3.3 & 2.6 \\
\hline Cereal and grain products & $146(100)$ & 2.4 & 1.7 \\
\hline Legumes and vegetables & $146(100)$ & 1.6 & 1.2 \\
\hline $\begin{array}{l}\text { Condiments and sauce (excluding non-iodised or } \\
\text { iodised salt) }\end{array}$ & $146(100)$ & 1.1 & 0.9 \\
\hline Sashimi and sushi & 48 (32.9) & 0.9 & 1.0 \\
\hline
\end{tabular}


TABLE 2. Characteristics of all 600 participants and the subgroup of participants who completed the FFQ

\begin{tabular}{|c|c|c|c|}
\hline \multirow[t]{2}{*}{ Characteristic } & \multicolumn{2}{|c|}{ Mean \pm SD, median (IQR), or No. (\%) } & \multirow[t]{2}{*}{$P$ value } \\
\hline & All participants $(n=600)$ & Subgroup with FFQ $(n=146)$ & \\
\hline Age (years) & $31.3 \pm 3.9$ & $30.5 \pm 3.7$ & 0.02 \\
\hline BMI $\left(\mathrm{kg} / \mathrm{m}^{2}\right)$ & $21.9 \pm 3.1$ & $22.1 \pm 3.3$ & 0.64 \\
\hline Gestational age (weeks) & $7.0(5.9-8.6)$ & $6.9(5.7-8.6)$ & 0.83 \\
\hline Nulliparous & $382(63.7)$ & $115(78.8)$ & $<0.001$ \\
\hline \multicolumn{4}{|l|}{ Education level ${ }^{\star}$} \\
\hline Tertiary (degree) & - & $44(30.3)$ & - \\
\hline Tertiary (diploma/certificate) & - & $22(15.2)$ & - \\
\hline Secondary or below & - & $79(54.5)$ & - \\
\hline \multicolumn{4}{|l|}{ Occupation* $^{*}$} \\
\hline Professional, administrator or managers & - & $21(14.4)$ & - \\
\hline Associate professional & - & $9(6.2)$ & - \\
\hline Clerical and service worker & - & $83(56.8)$ & - \\
\hline Unclassified $\dagger$ & - & $4(2.7)$ & - \\
\hline Housewife & - & $29(19.9)$ & - \\
\hline UIC ( $\mu \mathrm{g} / \mathrm{L})$ & $100(58-165)$ & $100(55-155)$ & 0.98 \\
\hline UICr $(\mu \mathrm{g} / \mathrm{g})$ & $98(67-150)$ & $93(66-144)$ & 0.65 \\
\hline
\end{tabular}

Abbreviations: $\mathrm{BMI}=$ body mass index; FFQ = food frequency questionnaire; $\mathrm{IQR}$ = interquartile range; $\mathrm{SD}$ = standard deviation; $\mathrm{UIC}=$ urinary iodine concentrations; $\mathrm{UICr}=$ urinary iodine-to-creatinine ratio

* Education level and occupation were only obtained in the subgroup of I 46 mothers who completed the FFQ

† Some participants did not identify their occupation

(a)

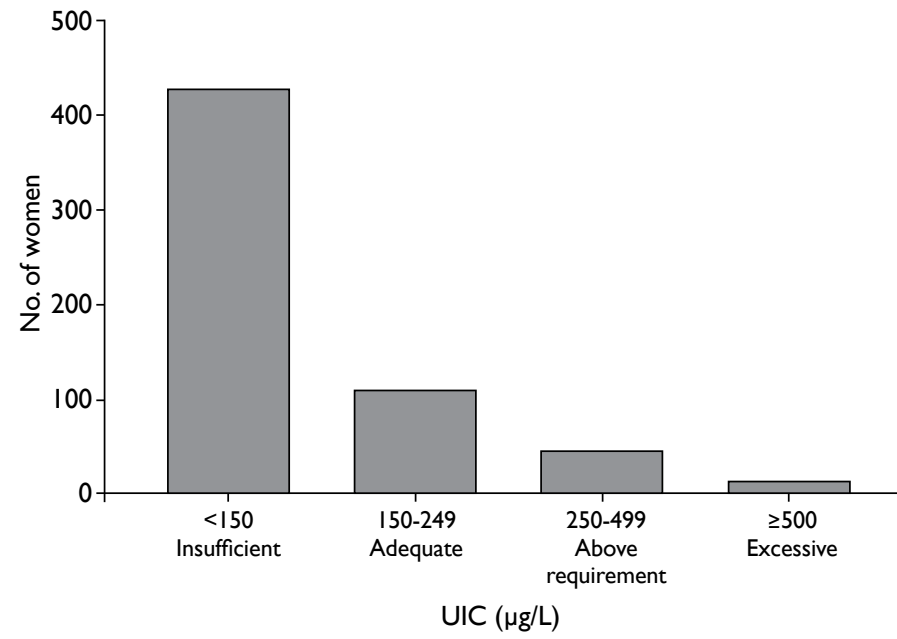

(b)

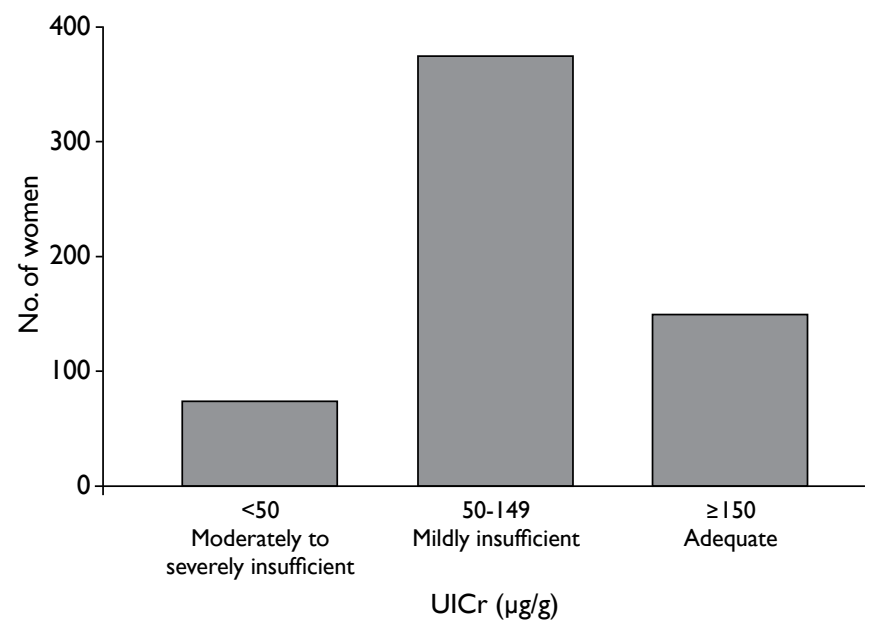

FIG. Subjects classified according to the WHO definition on the basis of (a) $\mathrm{UIC}$ and (b) $\mathrm{UICr}$ in the study population

Abbreviations: $\mathrm{UIC}=$ urinary iodine concentration; $\mathrm{UICr}=$ urinary iodine-to-creatinine ratio; $\mathrm{WHO}=$ World Health Organization

participants had UICr of $<150 \mu \mathrm{g} / \mathrm{g}$ (Fig b). ${ }^{7}$

Daily dietary intake of iodine was assessed in 146 participants. They were slightly younger in age and had a higher rate of nulliparity; their UIC and
UICr were no different to all participants (Table 2).

The median (IQR) daily dietary intake of iodine was $69.5(47.3-152.4) \mu \mathrm{g}$. The greatest source of iodine among the studied sample was from seaweeds that 
were consumed by $76 \%$ of women (Table 1 ). The next most common source of iodine was non-alcoholic beverages such as soy milk, soup, soft drinks, and water $(21.5 \%$ of the daily iodine intake). Of all the 146 women surveyed, only four $(2.7 \%)$ regularly used iodised salt in their diet. Several food sources were commonly eaten by all women including fish, cereal and grain products, vegetables and legumes, and condiments. Nonetheless these combined food sources only contributed to $15.5 \%$ of daily dietary iodine intake. There were 44 (30.1\%), 92 (63.0\%) and $122(83.6 \%)$ participants who had a daily iodine intake below 50,100, and $250 \mu$ g respectively.

Nutritional supplementation was reported by 414 (69.0\%) of all participants at the time of enrolment but only 163 (39.4\%) of these supplements contained iodine; the daily iodine supplement was between 140 and $290 \mu \mathrm{g}$ if taken according to the prescription. The subgroup of participants who had taken iodinecontaining supplements for 2 weeks or more had an adequate iodine status both by their median UIC and UICr (Table 3). In 122 subjects who completed the FFQ and had urinary iodine level measured within 1 week of each other, total daily iodine intake (iodine supplementation included) had a weak correlation with $\mathrm{UICr} \quad(r=0.20, \quad \mathrm{P}=0.03)$. In multivariate regression analyses, no covariates except gestational age at recruitment were associated with low UIC or UICr, or iodine supplementation; women recruited at a later gestational age had significantly higher UIC and were more likely to have started taking an iodine-containing supplement (Table 4).

\section{Discussion}

The findings from this study suggest that local pregnant women might still be iodine-deficient when the WHO definition is applied. In the subgroup of participants who completed the FFQ, more than $80 \%$ did not have an adequate daily iodine intake as recommended by the WHO and other authorities. ${ }^{13,14}$ This is in keeping with the survey conducted by the Centre for Food Safety 10 years ago. A recent local study of 95 lactating mothers showed that the mean daily dietary intake of iodine was $62.6 \mu \mathrm{g}$ with only $2 \%$ having a sufficient iodine intake. ${ }^{15}$ The result also showed that only $48 \%$ of breast milk samples from 39 women with an infant younger than 6 months had an adequate level of iodine ( $85 \mu \mathrm{g}$ per day) as recommended by the Chinese Dietary Reference Intake. ${ }^{15}$ The revised guideline from the Department of Health in 2016 suggested that mothers consider taking iodine-containing prenatal supplements during pregnancy and breastfeeding in view of the difficulties in obtaining sufficient iodine from food alone. ${ }^{16}$ The policy appears to be in agreement with our findings that mothers taking iodine-containing supplements were iodine sufficient according to their median UIC. Nonetheless universal iodine supplementation remains controversial. The American Thyroid Association, Endocrine Society, and New Zealand Ministry of Health recommend that women who are planning a pregnancy or who are currently pregnant or lactating should receive $150 \mu \mathrm{g}$ per day of iodine supplementation in the form

TABLE 3. Median UIC and UICr among participants who did not take iodine supplements and those who took it for more than I or 2 weeks

\begin{tabular}{|c|c|c|c|}
\hline & \multirow[t]{2}{*}{ No. of subjects } & \multicolumn{2}{|c|}{ Median (IQR) } \\
\hline & & UIC ( $\mu \mathrm{g} / \mathrm{L})$ & UICr $(\mu g / g)$ \\
\hline $\begin{array}{l}\text { Participants not taking supplement or taking } \\
\text { multivitamin supplement without iodine }\end{array}$ & 437 & $87(53-126)$ & $86(61-131)$ \\
\hline \multicolumn{4}{|l|}{ Participants taking iodine-containing supplement } \\
\hline$\geq 1$ Week & 106 & $165(96-228)$ & $142(105-266)$ \\
\hline$\geq 2$ Weeks & 83 & $165(97-241)$ & $155(105-275)$ \\
\hline
\end{tabular}

Abbreviations: IQR = interquartile range; UIC = urinary iodine concentration; UICr = urinary iodine-to-creatinine ratio

TABLE 4. Association of UIC, UICr, and iodine supplementation with gestational age at recruitment

\begin{tabular}{|c|c|c|c|c|c|}
\hline & \multicolumn{3}{|c|}{ Adjusted odds ratios $(95 \% \mathrm{Cl})^{\star}$} & \multicolumn{2}{|c|}{ Regression coefficient $(95 \% \mathrm{Cl})^{\star}$} \\
\hline & $\begin{array}{c}\text { lodine } \\
\text { supplementation }\end{array}$ & $\begin{array}{l}\text { Low UIC } \\
(<150 \mu \mathrm{g} / \mathrm{L})\end{array}$ & $\begin{array}{l}\text { Low UICr } \\
(<150 \mu \mathrm{g} / \mathrm{g})\end{array}$ & UIC ( $\mu \mathrm{g} / \mathrm{L})$ & UICr $(\mu g / g)$ \\
\hline Gestation age at recruitment (weeks) & $1.25(1.01$ to 1.56$)$ & 0.74 (0.58 to 0.93$)$ & $1.00(0.79$ to 1.26$)$ & $11.8(1.01$ to 22.5$)$ & $7.2(-3.2$ to 17.7$)$ \\
\hline$P$ value & 0.04 & 0.01 & 0.99 & 0.03 & 0.17 \\
\hline
\end{tabular}

Abbreviations: $\mathrm{CI}=$ confidence interval; $\mathrm{UIC}=$ urinary iodine concentration; $\mathrm{UICr}=$ urinary iodine-to-creatinine ratio

* Multivariate logistic and linear regression analyses adjusted for maternal age, parity, education level, occupation, and maternal body mass index 
of potassium iodide-containing supplements. ${ }^{17,18} \mathrm{On}$ the contrary, Cochrane systematic review did not support routine iodine supplementation in women before, during or after pregnancy, while WHO does not recommend iodine supplementation in regions where the median UIC indicates iodine sufficiency, or where a salt iodisation programme is in place.,19 All eight iodine-containing supplements that were reportedly taken by participants in this study also contained iron, and frequently resulted in varying degrees of constipation. Most women did not start taking supplements prior to their first antenatal visit. Even in those who did, $60 \%$ of the supplements contained no iodine, similar to that reported in the US..$^{20,21}$ Our results also show that mothers were more likely to have commenced iodine supplementation and have an iodine adequate status at a later gestation; this suggests mothers might acquire the knowledge as pregnancy progresses.

Although the UIC is designated for assessment of a population, not individual iodine status, our results suggest that three quarters of the participants may have been iodine insufficient during early pregnancy according to their UIC and UICr. Similarly, iodine deficiency in pregnancy has reemerged in several developed countries. ${ }^{22}$ Subjects enrolled into the Avon study in the UK were mildlyto-moderately iodine deficient with a median UIC of $91 \mu \mathrm{g} / \mathrm{L} .{ }^{7}$ A more recent study among schoolgirls in the UK also reported a similarly low UIC suggesting that mild-to-moderate iodine deficiency remains a problem..$^{23}$ Such deficiency was probably caused by a poor availability of iodised salt, few UK recommendations for increased iodine intake in pregnancy, and insufficient use of iodine-containing prenatal supplements. The International Council for Control of Iodine Deficiency Disorders global network now places the UK on the list of mildly deficient nations. ${ }^{24}$ The Department of Health in the UK has also added iodine to its National Diet and Nutrition Survey that checks the nutrient intake of adults and children in the UK. ${ }^{25}$ In Australia, mandatory iodine fortification of salt used in bread was introduced in 2009 in order to tackle mild iodine deficiency in the population; iodine status of women has improved since then but only those taking iodine-containing supplements have UIC indicative of sufficiency. ${ }^{26}$ According to data from the National Health and Nutrition Examination Survey 20052010 , more than $55 \%$ of pregnant women had UIC that suggested inadequate iodine intake. ${ }^{27}$ Mainland China has led the way in sustaining the elimination of iodine deficiency through iodised salt since the early $1990 \mathrm{~s}^{28}$ Nonetheless dietary iodine intake remains insufficient among pregnant women in Shanghai, Zhejiang, and other coastal cities where iodine is considered sufficient for the general population. ${ }^{29,30}$ A national survey from the Mainland reported that the median UIC levels of pregnant and lactating women were 123-224 $\mu \mathrm{g} / \mathrm{L}$ and 109-224 $\mu \mathrm{g} / \mathrm{L}$, respectively; median UIC was higher among those in inland cities, because of a higher iodine level in the salt and greater household coverage. ${ }^{31}$ In contrast, the progress in tackling iodine insufficiency in Hong Kong has been far from satisfactory.

Due to the limitations in study design, this study can only provide a snapshot overview of the iodine status of local pregnant women during early pregnancy from a single obstetric unit. Given that the main objective of the study was to ensure our study group had sufficient iodine intake in order to establish a thyroid function test reference range for the local population, our results cannot draw any conclusions about iodine status during the second and third trimesters. Moreover, dietary iodine intake could only be assessed in a subgroup of the population due to limited funding. The WHO has considered iodine deficiency the single most important preventable cause of brain damage worldwide. Recent study also highlighted the impact of iodine deficiency in the first 1000 days of life especially among breast-fed infants. ${ }^{32}$ As the Hong Kong SAR Government is actively promoting breastfeeding, it is also important to ensure adequate iodine in lactating mothers and breast-fed infants. It is time to systematically revisit the iodine status of our local women at pre-conception, and during pregnancy and lactation.

\section{Conclusions}

Results of our study are in line with those from the survey by the Centre for Food Safety, suggesting that our local pregnant women are borderline iodine-deficient and have an inadequate dietary iodine intake during early pregnancy. There is a need to educate the public and to advise women of childbearing age to maintain sufficient dietary iodine before contemplating pregnancy. A policy of salt iodisation and regular monitoring of iodine status with UIC in our population should be considered.

\section{Appendix}

Additional material related to this article can be found on the HKMJ website. Please go to <http:// www.hkmj.org $>$, and search for the article.

\section{Acknowledgements}

This study was supported by the Hospital Authority of Hong Kong on a project to derive a gestational age-specific thyroid function reference interval for the local pregnant population. Ms Sharon Lai-kwai Chan, research nurse, recruited all subjects, and collected and organised the clinical data. Ms Macy Kwan conducted face-to-face interviews for the dietary questionnaire for the subgroup of subjects. 


\section{Declaration}

All authors have disclosed no conflicts of interest.

\section{References}

1. World Health Organization; United Nations Children's Fund; International Council for the Control of Iodine Deficiency Disorders. Assessment of iodine deficiency disorders and monitoring their elimination: A guide for programme managers. 3rd ed. Available from: http://apps. who.int/iris/bitstream/10665/43781/1/9789241595827_ eng.pdf. Accessed 22 Mar 2017.

2. Kung AW, Chan LW, Low LC, Robinson JD. Existence of iodine deficiency in Hong Kong-a coastal city in southern China. Eur J Clin Nutr 1996;50:569-72.

3. Kung AW, Lao TT, Low LC, Pang RW, Robinson JD. Iodine insufficiency and neonatal hyperthyrotropinaemia in Hong Kong. Clin Endocrinol (Oxf) 1997;46:315-9.

4. Kung AW, Lao TT, Chau MT, Tam SC, Low LC. Goitrogenesis during pregnancy and neonatal hypothyroxinaemia in a borderline iodine sufficient area. Clin Endocrinol (Oxf) 2000;53:725-31.

5. But B, Chan CW, Chan F, et al. Consensus statement on iodine deficiency disorders in Hong Kong. Hong Kong Med J 2003;9:446-53.

6. Centre for Food Safety, Hong Kong SAR Government. Risk Assessment Studies Report No. 45: Dietary iodine intake in Hong Kong adults. Jul 2011. Available from: http://www.cfs.gov.hk/english/programme/programme_ rafs/programme_rafs_n_01_12_Dietary_Iodine_Intake_ HK.html. Accessed 20 Apr 2015.

7. Bath SC, Steer CD, Golding J, Emmett P, Rayman MP. Effect of inadequate iodine status in UK pregnant women on cognitive outcomes in their children: results from the Avon Longitudinal Study of Parents and Children (ALSPAC). Lancet 2013;382:331-7.

8. Hynes KL, Otahal P, Hay I, Burgess JR. Mild iodine deficiency during pregnancy is associated with reduced educational outcomes in the offspring: 9-year follow-up of the gestational iodine cohort. J Clin Endocrinol Metab 2013;98:1954-62.

9. Combet E, Lean ME. Validation of a short food frequency questionnaire specific for iodine in U.K. females of childbearing age. J Hum Nutr Diet 2014;27:599-605.

10. Condo D, Makrides M, Skeaff S, Zhou SJ. Development and validation of an iodine-specific FFQ to estimate iodine intake in Australian pregnant women. Br J Nutr 2015;113:944-52.

11. 楊月欣. 食物營養成分速查 [in Chinese]. 人民日報出版 社; 2006.

12. World Health Organization. Urinary iodine concentrations for determining iodine status in populations. 2013. Available from: http://www.who.int/vmnis/indicators/ urinaryiodine/en/. Accessed 22 Apr 2015.

13. Institute of Medicine (US) Panel on Micronutrients. Dietary reference intakes for vitamin $\mathrm{A}$, vitamin $\mathrm{K}$, arsenic, boron, chromium, copper, iodine, iron, manganese, molybdenum, nickel, silicon, vanadium, and zinc. Washington, DC: National Academies Press; 2001. Available from: https:// www.ncbi.nlm.nih.gov/books/NBK222310/. Accessed 22 Mar 2017.

14. American Thyroid Association. Iodine deficiency. 4 Jun 2012. Available from: http://www.thyroid.org/iodine- deficiency/. Accessed 25 Mar 2015.

15. PolyU discovers inadequate calcium, iron and iodine intakes of Hong Kong lactating women. 26 Jul 2016. Available from: https://www.polyu.edu.hk/web/en/media/ media_releases/index_id_6237.html. Accessed 25 Jun 2017.

16. Family Health Service, Department of Health, Hong Kong SAR Government. Healthy eating during pregnancy and breastfeeding. Revised Nov 2016. Available from: http:// www.fhs.gov.hk/english/health_info/woman/20036.html. Accessed 21 Jun 2017.

17. Alexander EK, Pearce EN, Brent GA, et al. 2017 Guidelines of the American Thyroid Association for the Diagnosis and Management of Thyroid Disease During Pregnancy and the Postpartum. Thyroid 2017;27:315-89.

18. Ministry for Primary Industries; Ministry of Health, New Zealand. Mandatory iodine fortification in New Zealand: Supplement to the Australian Institute of Health and Welfare 2016 report-Monitoring the health impacts of mandatory folic acid and iodine fortification. MPI Technical-Paper No: 2016/32. Available from: https://www.mpi.govt.nz/ dmsdocument/12786-mandatory-iodine-fortification-innew-zealand-supplement-to-the-australian-institute-ofhealth-and-welfare-2016-report-monitoring-the-healthimpacts-of-mandatory-folic-acid-and-iodine-fortification. Accessed 22 Mar 2017.

19. Harding KB, Peña-Rosas JP, Webster AC, et al. Iodine supplementation for women during the preconception, pregnancy and postpartum period. Cochrane Database Syst Rev 2017;(3):CD011761.

20. Gregory CO, Serdula MK, Sullivan KM. Use of supplements with and without iodine in women of childbearing age in the United States. Thyroid 2009;19:1019-20.

21. Leung AM, Pearce EN, Braverman LE. Iodine content of prenatal multivitamins in the United States. N Engl J Med 2009;360:939-40.

22. Li M, Eastman CJ. The changing epidemiology of iodine deficiency. Nat Rev Endocrinol 2012;8:434-40.

23. Vanderpump MP, Lazarus JH, Smyth PP, et al. Iodine status of UK schoolgirls: a cross-sectional survey. Lancet 2011;377:2007-12.

24. Iodine global network. Global Scorecard 2014: Number of iodine deficient countries more than halved in past decade. IDD Newsletter 2015;Feb:5-7. Available from: http://www. ign.org/cm_data/IDD_feb15_mail.pdf. Accessed $25 \mathrm{Mar}$ 2015.

25. Whitton C, Nicholson SK, Roberts C, et al. National Diet and Nutrition Survey: UK food consumption and nutrient intakes from the first year of the rolling programme and comparisons with previous surveys. Br J Nutr 2011;106:1899-914.

26. Charlton KE, Yeatman H, Brock E, et al. Improvement in iodine status of pregnant Australian women 3 years after introduction of a mandatory iodine fortification programme. Prev Med 2013;57:26-30.

27. Caldwell KL, Pan Y, Mortensen ME, Makhmudov A, Merrill L, Moye J. Iodine status in pregnant women in the National Children's Study and in U.S. women (15-44 years), National Health and Nutrition Examination Survey 20052010. Thyroid 2013;23:927-37.

28. Sun D, Codling K, Chang S, et al. Eliminating iodine deficiency in China: achievements, challenges and global implications. Nutrients 2017;9.pii:E361. 
29. Zou S, Wu F, Guo C, et al. Iodine nutrition and the prevalence of thyroid disease after salt iodization: a crosssectional survey in Shanghai, a coastal area in China. PLoS One 2012;7:e40718.

30. Wang Z, Zhu W, Mo Z, et al. An increase in consuming adequately iodized salt may not be enough to rectify iodine deficiency in pregnancy in an iodine-sufficient area of China. Int J Environ Res Public Health 2017;14:piiE206.

31. National Food Safety and Risk Assessment Expert
Committee. Salt iodization and risk assessment of iodine status in Chinese population [in Chinese]. Technical report No. 2010-002. May 2010. Available from: http://www. nhfpc.gov.cn/cmsresources/mohwsjdj/cmsrsdocument/ doc9250.pdf. Accessed 21 Jun 2017.

32. Stinca S, Andersson M, Herter-Aeberli I, et al. Moderateto-severe iodine deficiency in the "first 1000 days" causes more thyroid hypofunction in infants than in pregnant or lactating women. J Nutr 2017;147:589-95. 